\title{
Figuras y reminiscencias quevedianas en las Aguafuertes de Roberto Arlt
}

\author{
Fernando Rodríguez Mansilla \\ Hobart and William Smith Colleges \\ Spanish and Hispanic Studies Department \\ 208 Smith Hall \\ 300 Pulteney St. \\ Geneva, NY 14456 \\ EE. UU. \\ Mansilla@hws.edu
}

[La Perinola, (Issn: 1138-6363), 22, 2018, pp. 271-285]

DOI: $10.15581 / 017.22 .271-285$

Las Aguafuertes eran «notas» (así se refiere a ellas su autor) de un periodista, textos breves que conformaban una columna diaria en el periódico argentino El Mundo, entre 1928 y 1933. Las Aguafuertes podrían ser leídas como el carnet de un cronista de la sociedad porteña. En estos textos, Roberto Arlt disecciona personajes típicos, lo cual les otorga un aire costumbrista; ausculta con simpatía el mundo del crimen, que evoca la picaresca; y emite opiniones sobre la cultura argentina contemporánea, como el papel de las letras o la política. Las Aguafuertes tuvieron muchísimo éxito de lectoría y, gracias a ellas, Arlt logró vivir de su escritura. Además, empleó ese mismo formato para sus «notas» de viajero, entre España y Marruecos ${ }^{1}$.

En las Aguafuertes, Arlt delinea perfiles, caracteres y escenarios que se vuelven materia de tramas novelescas como las del díptico Los siete locos y Los lanzallamas, así como de El amor brujo y sus cuentos. Las Aguafuertes son un retablo de diversos oficios y tipos sociales, como el vago, el estafador, el mantenido, el ladrón de poca monta, la jovencita en edad de casarse, la mujer de la mala vida, etc. Si bien, según Roberto

1. Esos textos se suelen recopilar bajo los respectivos títulos de Aguafuertes españolas y Aguafuertes africanas. No existe edición de las aguafuertes que las recoja en toda su integridad, ya que, según comenta David Viñas, algunas páginas que albergan aguafuertes están rotas o rasgadas en los ejemplares de ElMundo conservados en la hemeroteca de la Biblioteca Nacional de Buenos Aires. Las ediciones antológicas de las aguafuertes son numerosas y generalmente las agrupan por temas, cuando abordan la realidad argentina, $o$ por el lugar del que hablan, cuando se trata de España y Marruecos. Al final de su edición de Aguafuertes, David Viñas ofrece una útil bibliografía, tanto de las principales ediciones de aguafuertes disponibles hasta 1998, como de los títulos de los textos originales aparecidos en El Mundo (estos últimos recopilados por Daniel Scroggins). 
Scari, «los blancos de la sátira de Arlt son esencialmente los de Quevedo y Larra, trasladados a un escenario argentino contemporáneo»², todos los personajes de las Aguafuertes provienen del panorama social de la época, que Arlt observaba con la mirada del flanêur, el escritor que ejercía «el placer de vagabundear» (como explica en un aguafuerte notable). Dicha mirada había sido influida por ciertas lecturas, entre las cuales sobresale la de la prosa satírica y picaresca de Quevedo, entre otros autores tan o más célebres (Cervantes, Mateo Alemán o el propio Víctor Hugo). El presente artículo ofrece un primer acercamiento a la presencia de Quevedo en las Aguafuertes de Roberto Arlt, aunque también haremos referencia, cuando sea oportuno, a su parcela novelesca. Se observa en los textos del argentino un desarrollo narrativo cercano al del modelo de la «figura» quevediana que Arlt plasma a través de una perspectiva satírica y su interés en el mundo del crimen.

Para empezar, el argentino desperdiga referencias a Quevedo como autor picaresco a través del Buscón. En su aguafuerte «El hombre de la camiseta calada», refiriéndose al marido, eterno desempleado, de la planchadora de barrio, Arlt exclama, en su elogio de la ociosidad de este personaje: «iCuándo aparecerá el Charles Louis Phillipe que describa nuestro arrabal tal cual es! iCuándo aparecerá el Quevedo de nuestras costumbres, el Mateo Alemán de nuestra picardía, el Hurtado de Mendoza de nuestra vagancia!»3. En otra aguafuerte, «La crónica no. $231 »$, reitera este canon en el apartado que titula «Mis maestros»:

Mis maestros espirituales, mis maestros de humorismo, de sinceridad, de alegría verdadera, son todos los días Dickens - uno de los más grandes novelistas que conoce y conocerá la humanidad- Eça de Queiroz, Quevedo, Mateo Alemán, Dostoievski -el Dostoievski de Stepamchikovo y sus habitantes- Cervantes y el mismo Anatole France. Con ellos, mis amigos invisibles, he aprendido a sonreír; y eso es mucho ${ }^{4}$.

Hasta aquí Arlt no lleva a cabo ninguna lectura realmente original de la picaresca, ya que está siguiendo la tendencia, propia del siglo $\mathrm{xx}$, de leer el libro del pícaro como si se tratase de ficciones realistas decimonónicas ${ }^{5}$; de allí que subsuma a Quevedo o a Alemán dentro del grupo selecto de novelistas como Dickens, Dostoievski o Eça de Queiroz. La picaresca, que Arlt identifica con el Buscón, es uno de sus criterios de lector para evaluar la calidad de la narrativa argentina contemporánea. Así lo revela cuando, comentando el libro de Enrique González Tuñón, La rueda del molino mal pintado, afirma que

2. Scari, 1976, p. 196.

3. Arlt, Aguafuertes, p. 45. Nótese que identifica a Diego Hurtado de Mendoza como autor del Lazarillo de Tormes, una atribución decimonónica que debió alcanzar en su infancia, dada su popularidad.

4. Arlt, Aguafuertes, p. 370

5. Smith, 1987 , pp. 88-89. 
la única superchería ingenua está en el título, porque el resto es tan bueno como una de esas páginas que sobre los antiguos pilletes escribieron Hurtado de Mendoza, Mateo Alemán, Cervantes en Rinconete y Cortadillo y Quevedo en ElBuscón ${ }^{6}$.

Esta mención del Buscón nos da pie a comentar algunas reminiscencias quevedianas en la primera novela de Arlt, El juguete rabioso (1926), empeño literario previo a las Aguafuertes?. El primer trabajo de Silvio Astier, el protagonista, es en la librería del avaro don Gaetano. Allí, el joven conoce a don Miguel, un anciano empleado de don Gaetano que cumple todo tipo de labores. Silvio llama a este personaje «Dío Fetente», por ser esta la interjección más frecuente en él. A don Miguel se le describe como "flaco, alto, carilargo, con barba de tres días en las fláccidas mejillas y expresión lastimera de perro huido en los ojos legañosos ${ }^{8}$. Este aspecto del personaje, que recuerda los rasgos principales del Dómine Cabra (sobre todo por su delgadez y descuido personal), armoniza con un ambiente donde priman el desgano y la suciedad.

En su primera noche en casa de don Gaetano, Silvio debe dormir en un camastro muy incómodo, que comparte con Dío Fetente. La escena nos recuerda inevitablemente a la «negra cama» del escudero de Lazarillo de Tormes'; pero en ese contexto hay, en realidad, dos sutiles referencias al Buscón. La primera es cuando Silvio concluye, tras observar donde va a dormir, que «indudablemente era cama de archipobre, un desecho de judería, la yacija más taimada que he conocido» ${ }^{10}$. Nótese el neologismo (archipobre» que proviene de la descripción del dómine Cabra, en la célebre frase (archipobre y protomiseria» ${ }^{11}$. A continuación, Silvio se envuelve en un tapete áspero que le impide dormir en esa cama que le está destrozando la espalda. Entonces llama a Dío Fetente, quien también está envuelto en otro tapete: “Como una tortuga, el anciano sacó su pequeña cabeza al aire de entre el caparazón de arpilleras ${ }^{12}$. La imagen de la cabeza que asoma como la de una tortuga quizás es un recuerdo de la estancia de Pablos en Alcalá: «Me acomodé entre dos colchones, y solo tenía media cabeza fuera, que pa-

6. Arlt, Aguafuertes, p. 382. El aguafuerte de la que procede el comentario es «El libro de los pelafustanes»).

7. El juguete rabioso puede leerse como una novela picaresca naturalizada argentina o una "picaresca porteña», como postulan Martínez Cutiño y Carricaburo (1979). Pese a asumir esta perspectiva para su análisis, los autores no comentan alusiones al Buscón o a otra novela picaresca de la época. Tan solo afirman, respecto del Rengo, que es «el personaje más próximo a la picaresca española» (1979, p. 1139).

8. Arlt, El juguete rabioso, p. 134.

9. Así lo observa Rita Gnutzmann en la introducción a su edición de Eljuguete rabioso (pp. 46-47). En esas mismas páginas, ella también refiere la descripción de «Dío Fetente», aunque no parangona a este personaje con el Dómine Cabra.

10. Arlt, El juguete rabioso, p. 139.

11. Quevedo, Buscón, p. 34. Este tipo de neologismo constituye un recurso estilístico propio de la lengua de Quevedo (Arellano, 1984, p. 203).

12. Arlt, El juguete rabioso, p. 139. 
recía tortuga» ${ }^{13}$. Con excepción del Buscón, no existen más referencias explícitas a obras concretas de Quevedo, pero contamos con una cita de memoria y algunas alusiones que nos permiten asumir, como veremos más adelante, la lectura arltiana de Los sueños y hasta quizás El libro de todas las cosas.

Veamos ahora la clasificación básica de las figuras, según las definió Quevedo en su opúsculo La vida de la corte. Las figuras "naturales» son aquellos individuos que poseen defectos físicos y las «artificiales», aquellos que «no solo no son lo que parecen [...], sino que además emplean su industria e ingenio [...] en aparentar lo que no son» ${ }^{14}$. Dentro de las figuras «naturales», la más constante en la obra de Arlt, más allá de las Aguafuertes, es el cojo. En el universo arltiano, el personaje que cojea se identifica con la malicia o la mala vida. Así, en El juguete rabioso, la cojera está vinculada, en primer lugar, con la iniciación literaria del protagonista. En el capítulo inicial, «Los ladrones», el zapatero andaluz que presta a Silvio literatura folletinesca (la cual alimenta su imaginación y deseos de gloria delincuencial) es (algo cojo, [con] una cojera extraña, el pie redondo como el casco de una mula con el talón vuelto hacia afuera» ${ }^{15}$. Con ese defecto físico, el zapatero es descrito como cascarrabias, sucio y cínico, apasionado de los folletines sobre bandoleros, como si fuera un Quevedo redivivo en su faceta satírica ${ }^{16}$. Silvio es consciente de la influencia nefasta de un personaje así, ya que su imagen le recuerda el proverbio que le había enseñado su madre: «Guárdate de los señalados de Dios» ${ }^{17}$.

Al final de la misma obra, el protagonista se encuentra nuevamente con un cojo, que lo adopta como su preceptor en el mundo picaresco del mercado del barrio: el Rengo será la gran figura que admira Silvio en la parte final de El juguete rabioso y a quien debe traicionar para culminar su proceso de degradación moral ${ }^{18}$. El Rengo es un personaje del lumpen cuyo defecto físico acrecienta en el lector la sensación de que es un sujeto que carga con el estigma de la mala vida, aunque finja estar rehabilitado. Del Rengo nos dice Silvio que, bajo la fachada de cuidador de carros, «tenía sus cascabeles de ladrón y siendo "macró" de afición no podía dejar de ser jugador de hábito. En substancia, era un

13. Quevedo, Buscón, p. 62.

14. Rubio Árquez, 2006, p. 290.

15. Arlt, El juguete rabioso, p. 87. Su aspecto asemejaría al de El patizambo de Jusepe Ribera.

16. No olvidemos que, ya en su época, los detractores de Quevedo le atribuían rasgos grotescos que lo identificaban como «diablo cojuelo» o bufón, con lo cual confundían su vida personal con su obra satírico-burlesca. Esta identificación ha perdurado en el mundo hispánico a través de los “chistes de Quevedo», por ejemplo (Iffland, 2004).

17. Arlt, El juguete rabioso, p. 87.

18. Silvio reflexiona sobre la delación como su caída en la infamia: «Y cuando no tenga nada que hacer, y esté triste pensando en el Rengo [después de traicionarlo], me preguntaré: ¿Por qué fui tan canalla? Y no sabré responderme, y en esta rebusca sentiré cómo se abren en mí curiosos horizontes espirituales» (El juguete rabioso, p. 227). 
pícaro afabilísimo, del cual se podía esperar cualquier favor y también alguna trastada» ${ }^{19}$. Se trata de un individuo nada confiable, como buen pícaro. Bajo la sombra del Buscón, podría identificarse al Rengo con un pícaro como Pablos, pues este también era ladrón, tahúr y proxeneta ${ }^{20}$.

Otros personajes con defectos físicos que aparecen en el universo de Arlt y podría cualificarse como figuras naturales son el bizco y el jorobado. Al primero le dedica el aguafuerte «El bizco enamorado», que arranca con toda una declaración de principios sobre su criterio para abordar a las figuras naturales: «Hay personas que tienen cierta prevención contra los cojos. Los creen malos, incapaces de una buena acción. Sin embargo, hoy he descubierto que un cojo es torta y pan pintado junto a un bizco sobre todo si se trata de un bizco enamorado ${ }^{21}$. El bizco del texto conforma una pareja grotesca al lado de su presunta novia, descrita como «una moza rubiona, cara de pseudo estrella cinematográfica ${ }^{22}$, es decir una muchacha un tanto falsa, según lo señalan el adjetivo despectivo («rubiona») y el adverbio («pseudo») que modifica negativamente su aparente vistosidad de artista famosa. Sentados ambos en el tranvía, el bizco se ve tan libidinoso y ridículo, intentando enamorarla con un discurso trillado que se identifica como “chamuyo» ('palabrería'), que produce, según el narrador, que las personas del tranvía piensen: «Te adornará la frente, querido bizco» ${ }^{23}$. En el texto de Arlt, el bizco concentra todos los vicios que puede tener un hombre que no acepta su realidad adversa frente a las mujeres:

19. Arlt, El juguete rabioso, p. 212.

20. El tercer personaje cojo destacado en la narrativa de Arlt es Hipólita, a la que se llama a veces «La coja» en el díptico de Los siete locos y Los lanzallamas. Su condición excepcional quizás se la otorga el hecho de que es mujer, lo cual la aleja de la imagen típica del cojo. Hipólita es la ex sirvienta y luego ex prostituta a la que el farmacéutico Ergueta pretende redimir mediante su matrimonio con ella. Después de que Ergueta enloquece y es internado en un hospicio, Hipólita conoce al Astrólogo, líder de una extraña conspiración de tintes fascistas que aspira a apoderarse del país, y se vuelve su amante. Al final de Los lanzallamas se dice que ambos están prófugos de la justicia. Difícil catalogar a Hipólita simplemente como maliciosa, ya que su femineidad le otorga otros matices, como el de una María Magdalena moderna. Encontramos un personaje como el farmacéutico Ergueta en las Aguafuertes. En «La decadencia de la receta médica», Arlt señala: «Tengo simpatías por los farmacéuticos. Son gentes que tienen conocimientos para poder fabricar bombas de dinamita, que a veces se ocultan bajo una pastilla de menta, y eso me merece un profundo respeto" (Aguafuertes, p. 153). En Los siete locos, Erdosain, el protagonista, se servía precisamente de Ergueta para proveerse de los insumos necesarios para crear sus bombas.

21. Arlt, Aguafuertes, p. 61.

22. Arlt, Aguafuertes, p. 61. Entre los varios sentidos de lo «grotesco» que pueden formularse, me parece oportuno el que ofrece Iffland para caracterizar la imagen grotesca en Quevedo, la cual involucra un choque entre lo cómico y lo incompatible con lo cómico (1978, p. 61). Esta pareja es grotesca porque muestra esa mezcla contradictoria entre lo feo, la seducción, la vulgaridad de la muchacha con sus aires de estrella y la falaz elegancia del bizco, en un contexto igualmente desfavorecedor para lo que ambos pretenden ser (una dama y un don Juan).

23. Arlt, Aguafuertes, p. 62. 
Un bizco no puede ser amado, porque por insensible que una mujer sea, se resiste ante ese espectáculo de un ojo atravesado que la espía como un foco infernal [...] Un bizco es más celoso que un turco y si no es celoso no es bizco [...] Indudablemente, un bizco enamorado es un espectáculo melodramático y tragicómico, sobre todo si se las tira de sentimental y gasta gafas y se peina con gomina ${ }^{24}$.

En el texto, la ridiculez del bizco no solo reside en que aspira al amor romántico, supuestamente inaccesible por su deformidad ocular, sino en que no admite su fracaso y se esfuerza en parecer un galán, con "gafas», que deberían darle un aire intelectual o sofisticado, y "gomina» propia del estereotipo masculino de estrella de cine. Para colmo, la mujer a la que pretende no parece ser tampoco un dechado de virtudes, sino una coqueta, pues «tenía unos ojazos que dicen "me gustan todos, todos, menos el que llevo al lado" $)^{25}$. El texto se cierra con la premonición del narrador en torno a un desenlace de infelicidad para esta extravagante pareja: «La moza rubiona miraba en redor como diciendo: "Dejen que vayamos al civil y verán luego cómo lo meto en vereda" »" Sus palabras, imaginadas por el narrador, pero coherentes de acuerdo con la imagen que nos ha dado de la muchacha como casquivana, prometen un matrimonio en el que el bizco será un cornudo y ella una manipuladora que siempre se saldrá con la suya. La displicencia del narrador frente a ese destino de los personajes involucra una censura moral hacia ambos, el bizco galante y la muchacha vulgar.

En torno al jorobado como figura a la manera de Quevedo, Arlt plasma su retrato en el cuento «El jorobadito»:

Todos los contrahechos son seres perversos, endemoniados, protervos... de manera que al estrangularlo a Rigoletto me creo con derecho a afirmar que le hice un inmenso favor a la sociedad, pues he librado a todos los corazones sensibles como el mío de un espectáculo pavoroso y repugnante. Sin añadir que el jorobadito era un hombre cruel $^{27}$.

El corcovado Rigoletto, cuyo auténtico nombre no conocemos, es una especie de bufón (de allí el nombre que le pone el protagonista) que vive de «levantar quinielas», es decir armar apuestas ilegales, apelando a su afabilidad y habla ridícula. Como le espeta el protagonista, Rigoletto es «un bufón y un parásito» ${ }^{28}$. El cuento incide en su animalización: «Por el cráneo parecía un mulo y por el semblante un caballo»; "aquel sapo humano me atraía con la inmensidad de su desparpajo»; «su amarilla dentadura de jumento» ${ }^{29}$. El protagonista se aprovecha de

24. Arlt, Aguafuertes, pp. 62-63.

25. Arlt, Aguafuertes, p. 61.

26. Arlt, Aguafuertes, p. 63

27. Arlt, «El jorobadito», El jorobadito, p. 20.

28. Arlt, «El jorobadito», El jorobadito, p. 33.

29. Arlt, «El jorobadito», El jorobadito, p. 25. 
este personaje extravagante para zafarse del compromiso con su novia, ya que teme caer en el matrimonio al que lo quiere arrastrar la madre de la joven. Al final, el jorobado (quien accede a participar en la celada por un poco de dinero), prosigue su papel hasta las últimas consecuencias, revelando toda su repugnancia. Ello conduce al protagonista a un rapto de locura, que lo lleva a estrangular a Rigoletto. El jorobado opera como un chivo expiatorio que encarna aquella crueldad que nos advertía el protagonista al inicio, con lo cual se pretende justificar por adelantado su muerte.

Resumiendo lo referido a las figuras naturales en la obra de Arlt, estas son esencialmente tres: el cojo, el bizco y el jorobado. Abundan ejemplos de cojos, por concentrar la maldad, y contamos solo con un ejemplo de las otras dos figuras. Las tres figuras naturales concentran repugnancia y fascinación al mismo tiempo, porque su deformidad representa la malicia (el cojo) o la necia ceguera del cornudo (el bizco), mientras que al jorobado se le asigna una crueldad que se plasma en el humor bufonesco. Estas figuras también se recrean con rasgos groseros y una fealdad física que refleja su inmoralidad, asociada con la vida del lumpen y la vagancia ${ }^{30}$.

Siguiendo con la clasificación de las figuras quevedianas, tras las figuras naturales contamos con las figuras artificiales, es decir aquellos que fingen ser lo que no son. Dentro de este segundo tipo, en las Aguafuertes destacan los ociosos o indolentes que apelan a su habilidad para engañar a los demás y vivir de sus dádivas ${ }^{31}$. Su maestría para hacerlo los convertiría casi en (flores de la corte», es decir, todos aquellos oficios que suponen «ardides de mal vivir»" ${ }^{32}$ Si bien la diferencia entre figuras y flores se encuentra en la ilegalidad en que se mueven los últimos ${ }^{33}$, en los textos de Arlt no se presenta esa distinción, por lo que subsumiremos a los personajes siguientes dentro de las «figuras artificiales», aunque admitamos que algunos tienen mucho de (flores».

Tras el ladrón de poca monta, los personajes masculinos favoritos de Arlt en las Aguafuertes son todos figuras artificiales que se dedican a vivir sin aparentemente trabajar: los ociosos como «el hombre corcho»,

30. Esta vida marginal se plasma en otro cuento de Arlt titulado «Las fieras». En este texto, se apela al nombre de «fieras» para caracterizar a «los hombres perdidos, ladrones y asesinos y mujeres que tienen la piel del rostro más áspera que cal agrietada» («Las fieras", El jorobadito, p. 111). Como fieras, los proxenetas casi no hablan, son violentos y están encerrados en el dolor de su deshumanización: «Fieras enjauladas, permanecemos tras los barrotes de los pensamientos residuos, y por eso es que la sonrisa canalla se despega tan dificultosamente del semblante encolado en una contracción de aburrimiento perrero» («Las fieras», El jorobadito, p. 119). La ausencia de sátira y ridiculización de estos personajes impide catalogarlos como figuras o reminiscencias quevedianas.

31. Así también lo percibe Scari, 1976, pp. 196-197: «Si tuviéramos que extraer de las Aguafuertes porteñas, del ideario arltiano todo, en realidad, el vicio que por encima de todos los demás provoca su mayor repugnancia, elegiríamos este de la indolencia».

32. Quevedo, Prosa festiva completa, p. 236.

33. Rubio Árquez, 2006, p. 291. 
que nunca se hunde gracias a su cinismo de gran simulador; «el hombre del apuro», que siempre está pidiendo dinero prestado; o «el hermanito coimero", el cual hace dinero con las propinas que le dan los novios de su hermana. Parece que nadie se salva del vicio de la vagancia en el universo arltiano, ya que hasta se observa, en el aguafuerte «Para ser periodista», que hay una conexión entre el oficio de periodista y el ocioso: «El periodismo, así entendido, es un oficio para vagos y para audaces» ${ }^{34}$.

En particular, Arlt dedica un aguafuerte, titulada (El parásito jovial», al «garronero», es decir el castizo gorrón (que él denomina "garrón»), personaje que le recuerda de inmediato a la picaresca:

Ya en el pícaro Guzmán de Alfarache aparece en Toledo la hermandad de los Caballeros de la Garra. Los Caballeros de la Garra se dedican a toda actividad estafadoresca, y no hay personaje con escudos y despensa bien puesta, que se escape a la voracidad de su garra. El buscavidas porteño y maleante bonaerense, de pronto descubrieron que ese gesto, zarpazo o golpe, merecía un calificativo extraordinario, y quizá algún andaluz redicho y perdulario, o algún ladrón erudito, encontró el término exacto y, de pronto, para definir el movimiento de apresar la cosa lo llamó «garrón»"35.

Lo cierto es que no existe tal episodio en el Guzmán de Alfarache. Arlt está confundiendo la estancia de Guzmán en Toledo, donde le pagó la cena a una cortesana y fue estafado por ella (pues no obtuvo sus favores $)^{36}$, con la descripción de las costumbres que ofrece don Toribio a Pablos de Segovia camino de Madrid en el Buscón. En su relato de las picardías del "garrón» traza su genealogía remontándose a los trucos que, según él, provienen del Guzmán:

Garrón, clásico garrón. Ya explicaba Guzmanillo las arterías del garronero. Siempre se presentaba a las casas cuando estaban almorzando, y si le preguntaban si había almorzado, contestaba que sí, pero, al rato, añadía:

- Come con tanta gracia vuestra excelencia, que le hace apetecer al harto. O si no:

- En verdad, huele tan bien este guisado, que no probarlo sería pecado ${ }^{37}$.

El pasaje citado saca a flote variadas lecturas picarescas. So capa de aludir al Guzmán, cuyas aventuras en Toledo vagamente recuerda, Arlt nos remite a don Toribio y sus maneras de comer gratis:

Si han empezado [a comer], decimos que sí [...] Diciendo esto, tomamos el cuchillo y partimos bocaditos [ejerciendo de maestresala], y al cabo decimos: «Oh, qué bien güele! Cierto que haría agravio a la guisandera en no

34. Arlt, Aguafuertes, p. 381.

35. Arlt, Aguafuertes, p. 129.

36. Alemán, Guzmán de Alfarache, pp. 241-244.

37. Arlt, Aguafuertes, p. 131. 
probarlo. iQué buena mano tiene!». Y diciendo y haciendo, va en pruebas el medio plato ${ }^{38}$.

El pasaje de Arlt también parece evocar la escena en la que el escudero del Lazarillo comenta lo bien que el pícaro come para insinuarle que tiene hambre y que le gustaría ser convidado: «Dígote Lázaro, que tienes en comer la mejor gracia que en mi vida vi a hombre, y que nadie te lo verá hacer que no le pongas gana aunque no la tenga ${ }^{39}$. Finalmente, los «caballeros de la garra» de los que habla Arlt provienen, en realidad, del Gil Blas de Santillana: el joven pícaro madrileño don Rafael cuenta que, al llegar a Toledo, con quince años,

hice presto conocimiento con dos mozuelos que me hicieron listo [...] Junteme también con ciertos caballeros de la garra, los cuales cultivaron tan felizmente mis buenas disposiciones familiares, que en poco tiempo llegué a ser uno de los más ricos caballeros de su orden ${ }^{40}$.

Otro vicio que irrita a Arlt es el de la arrogancia, el cual plasma en la figura del que habla todo el tiempo de haber nacido en una «cuna de oro». Como el autor del Cuento de cuentos, el argentino lleva a cabo la sátira lingüística, a veces mezclada con moralización. En el aguafuerte "Cuna de oro y pañales de seda», Arlt fustiga a los arrogantes que usan la susodicha muletilla para referirse a un falaz origen acomodado:

iGrandísimo turro! Vos habrás nacido en un corral y en una cuna de alfal$\mathrm{fa}$, no de oro. Cuando con tu estatura, tu jeta adulona, tus ojos grasientos y el bigotito atorrante que has echado, se tiene la audacia de decir que se ha nacido en cuna de oro, es indiscutible que tal cuna ha sido como un tacho de basura $^{41}$.

Con unos pocos adjetivos, Arlt traza al personaje con suma nitidez: la alusión a la estatura nos podría insinuar que es bajo (apelando así a la ruindad que se atribuye tradicionalmente a las personas pequeñas ${ }^{42}$ ); el vicio de la adulación se condena a través de la boca que se vuelve «jeta», despectivamente; en tanto los ojos son "grasientos», quizás para señalar que reflejan alcoholismo u otra enfermedad; el bigote se degrada y pierde cualquier elegancia con el diminutivo, al que se suma el adjetivo (atorrante», un argentinismo que significa 'vago'. La censura de Arlt se remata con el contraste entre la falsa «cuna de oro» como frase hecha del arrogante que es, según la mirada satírica, un auténtico «tacho de basura».

38. Quevedo, Buscón, p. 156.

39. Lazarillo de Tormes, p. 89.

40. Lesage, Gil Blas de Santillana, p. 219.

41. Arlt, Aguafuertes, p. 122.

42. La idea de las personas bajas como ruines se encuentra en el Sueño del juicio final de Quevedo, aunque no es original suya, naturalmente (Los sueños, p. 102). 
Queda evidente que, en su escritura, Arlt no deja de aprovechar los recursos de la lengua para examinar los tipos sociales. Otra figura artificial es la vieja hipócrita, cuyo retrato es enmarcado por el uso de otra frase trillada, que da título a la aguafuerte respectiva. En «¿No se lo dije yo?», el comentario de la susodicha frase le da a Arlt pie a criticar a la «anciana metomentodo», la vecina perspicaz y chismosa que «ve con más claridad en las vidas de los otros que en la propia» ${ }^{43}$.

En la misma senda de la reflexión acerca de la lengua contemporánea, Arlt revela su plena consciencia de que el lunfardo, el habla popular de Buenos Aires, es equivalente a la germanía aurisecular. En su prólogo a Los lanzallamas, el autor recogía la opinión muy difundida entre sus detractores acerca de su pobre lenguaje literario, por recoger precisamente el lunfardo: «Se dice de mí que escribo mal»44. En el aguafuerte «¿Cómo quieren que les escriba?», Arlt afirma sentirse autorizado por el ejemplo de sus autores clásicos favoritos, refiriéndose nuevamente a Quevedo como paradigma: "Quevedo, así como Cervantes en las Novelas ejemplares usan la "germanía", el gitano o el caló hasta cansarse, y no hablemos de los escritores actuales» ${ }^{45}$. Bajo esta consigna, Arlt se siente cómodo analizando el lenguaje popular para entender cómo funciona la sociedad. Observemos su comentario sobre el concepto de "furbo» (en el texto del mismo nombre), que encierra el de pícaro vividor, otra figura artificial que encuentra en Buenos Aires:

Como se ve, la palabra «furbo», en italiano, expresa la índole psicológica de un sujeto y se refiere categóricamente a esa virtud que inmortalizó Ulises, y que hizo se le llamara el Astuto o Sutil. Hoy Ulises no sería el astuto ni el sutil, sino que lo llamaríamos sintéticamente «un furbo». Vemos en él simbolizadas las virtudes de esa raza de vagos y atorrantes, que se pasaban el día pleiteando en el ágora, y que eran unos solemnes charlatanes. Porque los griegos fueron eso. Unos charlatanes. Se caracterizaban por la vagancia disciplinada y por la pillería en todos sus actos. Malandrines de la antigüedad, infiltraron la estética en los países sanos, y como la manzana podrida, descompusieron el robusto y burgués imperio romano. Y isaben ustedes por qué? Porque los griegos eran unos «furbos» ${ }^{46}$.

Con esta mirada mordaz sobre el mundo clásico, Arlt se introduce en la degradación de los mitos, una lección que, nuevamente, podría remontarse a su lectura de Quevedo. Este último, para censurar la comparación de Jesucristo con Ulises que hizo Pérez de Montalbán, decía en La Perinola que «los propios gentiles idólatras le llamaron [a Ulises] engañador, embustero y mentiroso. Ya se ve en Homero que repetidamente le nombra lleno de engaños y engañador; y en Sófocles, Minerva

43. Arlt, Aguafuertes, p. 126.

44. Arlt, Los siete locos. Los Lanzallamas, p. 285.

45. Arlt, Aguafuertes, p. 372.

46. Arlt, Aguafuertes, p. 64. 
le llama cazador de engaños y engañador» ${ }^{47}$. ¿Conocería Arlt esta referencia de Quevedo en torno a Ulises? No lo sabemos. Sin embargo, la perspectiva que rebaja al personaje es compartida y se encuentra fuertemente enlazada, dentro su texto, con la influencia de Quevedo (hecha explícita citándolo como ejemplo) y la interpretación de la realidad cotidiana a través de su paradigma para autorizar ciertos usos lingüísticos. Arlt logra entonces, en su escritura, plasmar una lengua literaria que se alimenta de lo popular, pero cuyas raíces son eminentes, ya que se remontan a los clásicos, entre ellos Quevedo. Es su forma de defenderse frente a los críticos. Además, le otorga reverberaciones literarias, en clave cómica, a la vida cotidiana: el «furbo» es un Ulises degradado.

Más interesante se presenta la probable lectura de Los sueños quevedianos, según se trasluce en las Aguafuertes. En «El placer de vagabundear», Arlt narra cómo en sus paseos la ciudad se vuelve oscura, siniestra, adoptando los tonos de las pinturas negras de Goya, quien «como animador de la canalla de Moncloa, de las brujas de Sierra Divieso, de los bigardos monstruosos, es un genio. $\mathrm{Y}$ un genio que da miedo» ${ }^{48}$. A continuación, Arlt describe su visión de la ciudad como un infierno:

La ciudad desaparece. Parece mentira, pero la ciudad desaparece para convertirse en un emporio infernal. Las tiendas, los letreros luminosos, las casas quintas, todas esas apariencias bonitas y regaladoras de los sentidos, se desvanecen para dejar flotando en el aire agriado las nervaduras del dolor universal. Y del espectador se ahuyenta el afán de viajar. Más aún: he llegado a la conclusión de que aquel que no encuentra todo el universo encerrado en las calles de su ciudad, no encontrará una calle original en ninguna de las ciudades del mundo. Y no las encontrará, porque el ciego en Buenos Aires es ciego en Madrid o Calcuta... ${ }^{49}$

El pasaje recuerda el esquema quevediano de la calle mayor por la cual desfilan las diversas figuras o tipos sociales, cuya hipocresía y vicios quedarán revelados bajo la mirada satírica del narrador ${ }^{50}$. Arlt apunta a la falsedad de lo que encuentra a su paso, como aquellos «letreros luminosos» $\mathrm{o}$ «todas esas apariencias bonitas y regaladoras de los sentidos», que bien vistos son indicio del «dolor universal $»^{51}$.

Ahora bien, a propósito de esta reminiscencia, ¿cómo sostener una lectura arltiana de Los sueños? Ya vimos más arriba que Arlt suele apelar a la memoria cuando refiere sus lecturas y puede confundirse, como le ocurre con Guzmán de Alfarache y Gil Blas. He aquí que su texto «Fauna tribunalesca» se abre con una cita de Quevedo:

47. Quevedo, Prosa festiva completa, p. 499.

48. Arlt, Aguafuertes, p. 116.

49. Arlt, Aguafuertes, p. 116.

50. Así se observa en El mundo por de dentro (Los sueños, pp. 275-276).

51. Scari encuentra en cuna imagen de pecadores basada en la comicidad que entrañan» el rasgo común entre las Aguafuertes, Los sueños y los personajes del octavo círculo del Infierno de Dante (1976, p. 200). 
Bien lo dijo Quevedo: «Abogados y escribanos son aprendices de tósigo y ponzoña graduada», queriendo dar a entender con ello que era preferible sufrir la acometida de un toro furioso a entrar en relaciones con semejantes bicharracos, despojadores de viudas y enemigos natos del huérfano ${ }^{52}$.

Se trata de una cita tergiversada, seguramente sin intención. En realidad, Quevedo escribe en el Sueño del infierno: «No digo esto porque fuese menor el batallón de los doctores, a quien nueva elocuencia llama ponzoñas graduadas, pues se sabe que en sus universidades se estudia para tósigos» ${ }^{53}$. En la sátira quevediana, la identificación con la ponzoña es propia de los médicos, no de leguleyos, aunque es comprensible que Arlt los confunda, ya que en el texto del Sueño del infierno aparecían, justo antes, los letrados. Además, es posible que en su memoria "doctor» pudiera hacerlo imaginar, de inmediato, en un abogado. Con todo, el pasaje no deja de ser revelador de cómo Arlt, mediante la cita inexacta, se apropia de un mecanismo del humor quevediano para sus propios intereses, trasladando el chiste del médico al experto en leyes, el cual puede ser, a sus ojos, tan mortal como el galeno. Arlt desarrolla el mismo concepto, la capacidad de matar de los letrados, en su crítica a los escribanos y abogados:

Me explico que estas columnas [necrológicas] se las lea un escribano, que es predecesor del sepulturero, ya que en sus bolsillos encuentra sepultura nuestro dinero; me explico que se lean esas listas los abogados, que contribuyen a menguar nuestra vida con la longitud de sus pleitos ${ }^{54}$.

Junto al ataque a los letrados, no podía faltar en el discurso satírico de Arlt el tradicional tema del matrimonio, que se expresa a través de la misoginia. El tratamiento del asunto es igualmente caro a Quevedo y pueden encontrarse algunos puntos de contacto entre ambos. «En Buenos Aires los "dorimas" ['maridos'] son esclavos de sus esposas», afirma Arlt, rotundo, en “Esmeralda, Corrientes y Pellegrini» ${ }^{55}$. En las Aguafuertes la mirada misógina exige que la mujer sea ignorante, astuta y aprovechada; mientras la joven descocada sueña con ser artista. Así, «la mujer tiene una antipatía instintiva por el hombre inteligente. Sabe que podrá engañarlo relativamentes ${ }^{56}$. Bajo esta perspectiva, el único objetivo de la fémina, cuando está en edad de merecer, después de que olvida su sueño de ser estrella, es casarse, meta compartida y auspiciada por sus padres, porque “Lo esencial es casarse», como reza el título de una de las aguafuertes en la que Arlt recoge las palabras de una mujer «reporteada»:

52. Arlt, Aguafuertes, p. 139.

53. Quevedo, Los sueños, p. 176.

54. Arlt, Aguafuertes, p. 225.

55. Arlt, Aguafuertes, p. 257.

56. Arlt, «Primeras palabras para conquistar a una dama», Aguafuertes, p. 309. 
[Las mujeres] no tienen la culpa. Están criadas así. Han visto la vida así. Desde chicas oyen hablar del matrimonio. [...] Para estas mujeres criadas con semejante criterio, no puede haber nada más que un final: casarse. Casarse es resolver el problema económico y un montón de problemas. Y como casarse es lo esencial, lo esencialísimo, usted se da cuenta que lo que menos interviene en dicha operación es el amor $^{57}$.

En otro aguafuerte, de título «Quiero casarme!», Arlt enfatiza que la causa de esta obsesión reside en una educación falsa: «Si a la rutina de la vida se puede definir como "educación", porque, hablando en plata, tal "educación" no existes ${ }^{58}$. Aunque no desarrolla este punto, porque escapa al discurso satírico proponer reformas, se deja entrever en sus textos que abogaría por oportunidades educativas de verdad para la mujer, que le permitan tener mayores perspectivas que solo el matrimonio como objetivo vital.

Si Arlt se solidariza con la mujer como sujeto que no tiene más opciones en la vida, no deja de apuntalar al marido como víctima también de esta presión social. El matrimonio como amargo tema de crítica social será plasmado por Arlt en sus novelas de madurez. En Los siete locos, el protagonista es abandonado por su mujer, quien se va con un militar, símbolo del poder masculino, en contraste con el arruinado marido, Remo Erdosain, el cornudo. En su última novela, El amor brujo, encontramos un cambio en el enfoque: la trama se plantea como una celada para casar al ingeniero Balder, aparentemente un hombre maduro e inteligente, con una muchacha, la virginal Irene. Por ello, el título de la novela es revelador: el amor es brujo porque hechiza, engaña a los involucrados. De esa forma, El amor brujo desarrolla la vieja historia del burlador burlado, pues Balder creía estar aprovechándose de Irene, cuando en realidad la joven y los adultos hipócritas a su alrededor conspiran para conducir al pretendiente hacia el matrimonio con ella.

Para encarnar todos los temores del hombre hacia el matrimonio y sus miserias, Arlt inventó el personaje del cándido Bonafide («buena fe») en el aguafuerte del mismo nombre: el ingenuo novio cornudo al que la muchacha y su madre (retratada como toda una Celestina) manipulan para que le tolere la infidelidad. Bonafide se muestra cercano al maridillo quevediano, aunque con matices: un cornudo sufrido, pero no exactamente voluntario ni industrioso ${ }^{59}$. Bonafide se enfada con la novia, a quien reprocha haberlo engañado quizás con más de uno. Esta explota, con sollozos y gritos, para llamar la atención de la madre, «vieja conqueridora de voluntades, experta en embrujos domésticos» para «los pretendientes refractarios al casorio» ${ }^{60}$. También llamada "zurcidora de voluntades», en frase que evoca La Celestina, la madre consuela a la hija

57. Arlt, Aguafuertes, pp. 311-312.

58. Arlt, Aguafuertes, p. 318.

59. Arellano, 1984, pp. 69-70.

60. Arlt, Aguafuertes, p. 347. 
y logra hacer sentir culpable a Bonafide y aceptar la infidelidad prácticamente como si fuera un error suyo y no responsabilidad de la joven.

Una última posible asimilación del estilo de Quevedo se observa en la descripción sucinta de Arlt de las particulares figuras de Buenos Aires, como aquella del enfermo que vive de su mal en «El enfermo profesional». Nótese cómo la imagen incorpora algunos rasgos grotescos, con el gigantismo y el color amarillento, y que el estilo recuerda el modelo del Libro de todas las cosas, con sus verbos en imperativo que asemejan a instrucciones, para que sea sencillo para el lector descubrir el embuste al que puede ser sometido:

El que cuente con un físico de esta naturaleza, dos metros de altura, cuello de escarbadientes y color de vela de sebo puede comenzar la farsa de la enfermedad (siempre que sea empleado nacional) tosiendo una hora por la mañana en la oficina. Alternará este ejercicio de laringe con el tocarse suavemente la espalda haciendo al mismo tiempo un gestecillo lastimero. Luego toserá dos o tres veces más, y con todo disimulo, evitando que lo vean (para que lo miren) se llevará el pañuelo a la boca y lo ocultará prestamente ${ }^{61}$.

Como típica figura artificial, este individuo que parece cosificado (“cuello de escarbadientes», (color vela de sebo») hace de la farsa su medio de subsistencia, hasta convertirla en un arte sutil: emplea primero la exageración y la lástima, luego el disimulo y aquella habilidad de pretender actuar con descuido para precisamente llamar la atención sobre sí mismo. Este es un estafador que aprovecha su puesto de funcionario (ya que se debe ser «empleado nacional» para que funcione) como otras figuras callejeras engañan para vivir como parásitos.

Hemos observado cómo el narrador de las Aguafuertes examina tipos sociales de la gran Buenos Aires, diseccionando su aspecto y sus acciones. Se trata, ciertamente, de "personajes genéricos presentados mediante un perspectivismo deshumanizante que deforma y exagera ciertas características a fin de destacar un vicio moral ${ }^{62}$, pero esta deshumanización se inspira en recursos estilísticos (morfología, léxico, frases hechas), temas y alusiones a la obra de Quevedo. Bajo la influencia manifiesta de la picaresca representada por el Buscón, así como a través de textos satíricos suyos (con seguridad Los sueños), Roberto Arlt abraza un patrón estilístico y unos temas que nos recuerdan a las figuras naturales y artificiales que pululaban en la corte madrileña, vueltos ahora sujetos risibles y estafadores de la capital de Argentina. Como Quevedo, Arlt los ausculta para ejercer la crítica social y advertir a su lector de los peligros que lo acechan en una infernal Buenos Aires.

61. Arlt, Aguafuertes, p. 190.

62. Varela, 2002, pp. 149-150. 


\section{Bibliografía}

Alemán, Mateo, La obra completa. 3. Guzmán de Alfarache, ed. David Mañero Lozano, Madrid / Frankfurt Am Main, Iberoamericana / Vervuert, 2014.

Arellano, Ignacio, Poesía satírico-burlesca de Quevedo. Estudio y anotación filológica de los sonetos, Pamplona, Eunsa, 1984.

Arlt, Roberto, El jorobadito, Buenos Aires, Compañía General Fabril Editora, 1968.

Arlt, Roberto, El juguete rabioso, ed. Rita Gnutzmann, Madrid, Cátedra, 2001.

Arlt, Roberto, Obras. Tomo II. Aguafuertes, ed. D. Viñas, Buenos Aires, Losada, 1998.

Arlt, Roberto, Los siete locos. Los lanzallamas, ed. Mario Goloboff, París / Madrid, ALLCA Xx / Galaxia Gutenberg / Círculo de Lectores, 2000.

Iffland, James, Quevedo and the Grotesque, I, London, Támesis Books Limited, 1978.

Iffland, James, “"Todos somos locos / los unos y los otros": Quevedo con cascabeles», en Quevedo en Manhattan, ed. Ignacio Arellano y Victoriano Roncero, Madrid, Visor, 2004, pp. 141-164.

Lazarillo de Tormes, ed. Francisco Rico, Madrid, Cátedra, 2000.

Lesage, Alain-René, Gil Blas de Santillana, trad. J. F. De Isla, Paris, Baudry, 1843.

Martínez Cutiño, Luis y Norma Carricaburo, “Una picaresca porteña: El juguete rabioso de Roberto Arlt», en La picaresca. Orígenes, textos y estructuras, Madrid, Fundación Universitaria Española, 1979, pp. 1137-1143.

Quevedo, Francisco de, La vida del buscón llamado don Pablos, ed. Fernando Lázaro Carreter, Salamanca, Universidad de Salamanca, 1965.

Quevedo, Francisco de, Los sueños, ed. Ignacio Arellano, Madrid, Cátedra, 1999.

Quevedo, Francisco de, Prosa festiva completa, ed. Celsa Carmen García Valdés, Madrid, Cátedra, 1993.

Rubio Árquez, Marcial, «De La vida de la Corte a La vida del Buscón», La Perinola, 10, 2006, pp. 287-296.

Scari, Roberto, «Tradición y renovación en las aguafuertes porteñas de Roberto Arlt», Anales de Literatura Hispanoamericana, 5, 1976, pp. 195-207.

Smith, Paul Julian, «The Rhetoric of Representation in Writers and Critics of Picaresque Narrative: Lazarillo de Tormes, Guzmán de Alfarache, El Buscón», Modern Language Review, 82, 1987, pp. 88-108.

Varela, Fabiana Inés, "Aguafuertes porteñas: tradición y traición de un género», Revista de Literaturas Modernas, 32, 2002, pp. 147-166. 



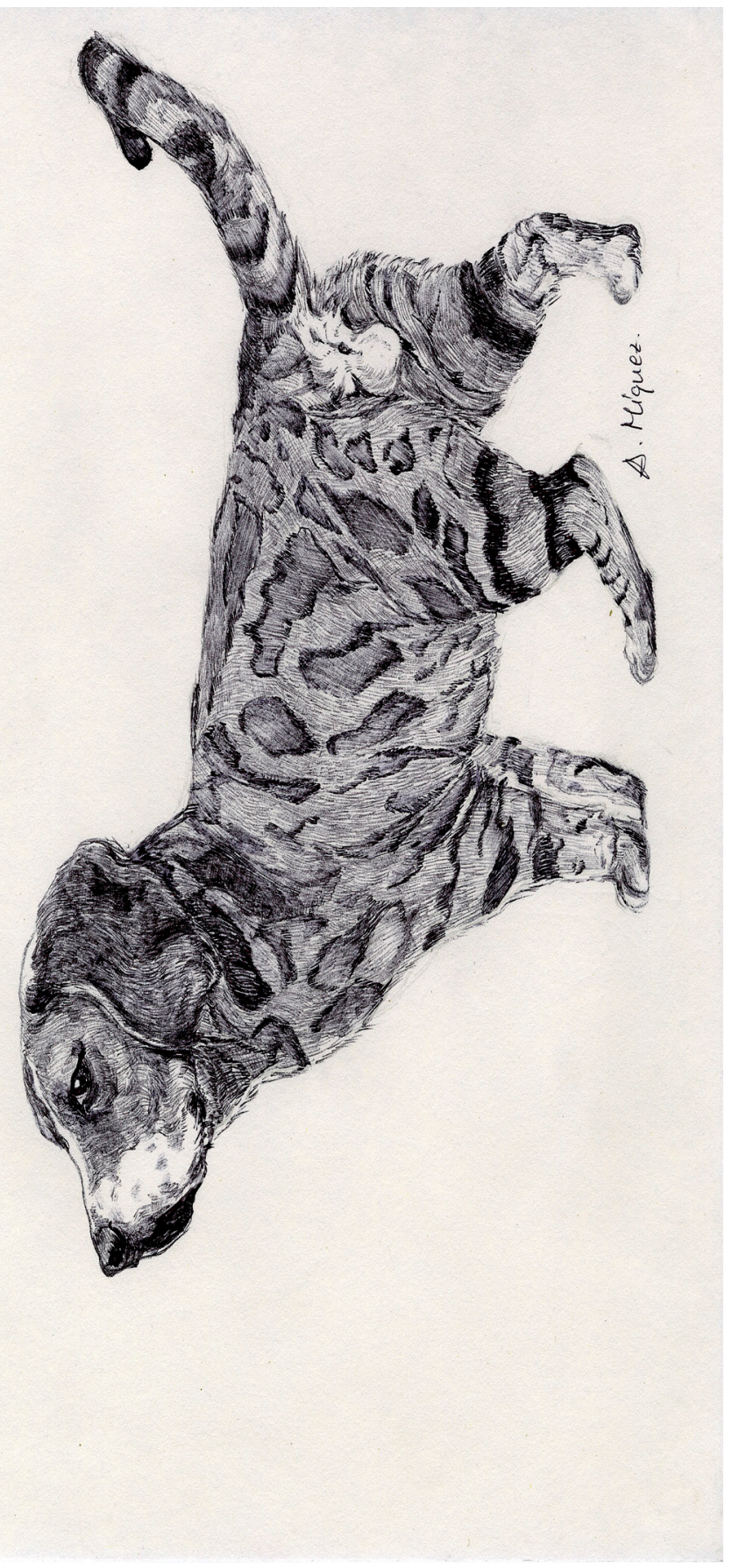


